\title{
Arteriolar insulin resistance in a rat model of polycystic ovary syndrome
}

\author{
Levente Sara, M.D., ${ }^{a}$ Peter Antal, M.D., ${ }^{b}$ Gabriella Masszi, M.D., ${ }^{d}$ Anna Buday, M.D., ${ }^{c}$ Eszter M. Horvath, M.D., Ph.D., \\ Peter Hamar, M.D., Ph.D., ${ }^{c}$ Emil Monos, M.D., Ph.D., D.Sc., ${ }^{\mathrm{b}}$ Gyorgy L. Nadasy, M.D., Ph.D., \\ and Szabolcs Varbiro, M.D., Ph.D. ${ }^{a}$ \\ a Second Department of Obstetrics and Gynecology, ${ }^{b}$ Institute of Human Physiology and Clinical Experimental Research, ${ }^{c}$ Department of \\ Pathophysiology, Semmelweis University Budapest, and ${ }^{d}$ Department of Cardiology, Bajcsy-Zsilinszky Hospital, Budapest, Hungary
} Objective: To investigate the vascular dysfunction caused by insulin resistance in polycystic ovary syndrome (PCOS) and the effectiveness of vitamin D
in an animal model.
Design: Controlled experimental animal study.
Setting: Animal laboratory at a university research institute.
Animal(s): Thirty female Wistar rats.
Intervention(s): Rats were divided into groups at age $21-28 \mathrm{weeks}$. Twenty of them were subjected to dihydrotestosterone (DHT) treatment ( $83 \mu \mathrm{g} / \mathrm{d})$; ten
of them also received parallel vitamin D treatment $(120 \mathrm{ng} / 100 \mathrm{~g} / \mathrm{wk})$. Oral glucose tolerance tests with insulin level measurements were performed. Gra-
cilis arterioles were tested for their contractility as well as their nitric oxide (NO)-dependent and insulin-induced dilation using pressure arteriography.
Main Outcome Measure(s): Several physiologic parameters, glucose metabolism, and pressure arteriography.
Result(s): DHT treatment increased the passive diameter of resistance arterioles, lowered norepinephrine-induced contraction (30.1 $\pm 4.7 \%$ vs. $8.7 \pm$
3.6\%) and reduced acetylcholine-induced (122.0 $\pm 2.9 \%$ vs. $48.0 \pm 1.4 \%$ and insulin-induced (at 30 mU/mL: $21.7 \pm 5.3$ vs. $9.8 \pm 5.6 \%)$ dilation.
Vitamin D treatment restored insulin relaxation and norepinephrine-induced contractility; in contrast, it failed to alter NO-dependent relaxation.
Conclusion(s): In DHT-treated rats, in addition to metabolically proven insulin resistance, decreased insulin-induced vasorelaxation was observed and
was improved by vitamin D treatment without affecting NO-dependent relaxation. The reduction in insulin-induced dilation of arterioles is an important
as yet undescribed pathway of vascular damage in PCOS and might explain the clinical effectiveness of vitamin D treatment. (Fertil Steril ${ }^{\circledR} 2012$;

- $\mathbf{n}$. C2012 by American Society for Reproductive Medicine.)

Key Words: PCOS, vascular insulin resistance, vitamin D, arteriole

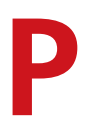
olycystic ovary syndrome (PCOS) affects 5\%-8\% of fertile women. It is already well known that increased insulin resistance and altered metabolic status occur in these patients. PCOS also alters cardiovascular function through various mechanisms $(1,2)$.

In 2000, Lakhani and Hardiman suggested that in women with PCOS, the internal carotid artery pulsatility index is decreased and cardiovascular risk increased $(3,4)$. Since then, it has been shown that women with PCOS have an early increased prevalence of atherosclerosis, metabolic syndrome, insulin resistance and type 2 diabetes
$(1,2)$. The mechanisms underlying this increased risk and possible therapeutic approaches are still subjects of investigation. Human studies have shown microvascular dysfunction in PCOS, as indicated by reductions in acetylcholine (Ach)-dependent vasodilation. This impaired response to Ach is similar to that which has been observed in noninsulin-dependent diabetes mellitus and is supposed to relate to the metabolic alterations, particularly the insulin resistance, of PCOS (5).

In PCOS, glucose metabolism can be improved with insulin sensitizers, and the positive vascular effects of

Received September 18, 2011; revised November 3, 2011; accepted November 14, 2011.

L.S. has nothing to disclose. P.A. has nothing to disclose. G.M. has nothing to disclose. A.B. has nothing to disclose. E.M.H. has nothing to disclose. P.H. has nothing to disclose. E.M. has nothing to disclose. G.L.N. has nothing to disclose. S.V. has nothing to disclose.

Supported by the Hungarian Society of Hypertension and Hungarian National Grant OTKA TO32019.

Reprint requests: Levente Sara, M.D., Second Department of Obstetrics and Gynecology, Faculty of Medicine, Semmelweis University, H-1083, Üllői Str 78/A, Budapest, Hungary (E-mail: saralevente@gmail.com); and Szabolcs Varbiro, M.D., Ph.D., Second Department of Obstetrics and Gynecology, Faculty of Medicine, Semmelweis University, H-1083, Ulloi Str 78/A, Budapest, Hungary (E-mail: varbiroszabolcs@gmail.com).

these therapies are largely known $(6,7)$. Vitamin D may be also used as adjuvant therapy in women with PCOS (8). The positive effects of vitamin D administration on glucose metabolism $(9,10)$ and the reduction of cardiovascular complications (11, 12) are known, but vitamin $D$ is not yet commonly used in PCOS therapy.

To understand the pathologic mechanisms of PCOS and make timely therapeutic interventions, it is necessary to concentrate on earlier stages of the disease. Manneras et al. developed a model for human PCOS by giving dihydrotestosterone (DHT) to adolescent female rats. After 90 days, this treatment altered ovarian morphology and vital parameters; early impairment of glucose metabolism was also found. The authors suggested that the DHT model is suitable for studies of the metabolic and ovarian features of the syndrome $(13,14)$.

The aim of the present study was to determine the early effects of DHT treatment on glucose metabolism and arteriolar function before the appearance of 
hypertension. We also examined the potentially beneficial effects of vitamin D.

We had previously studied the vascular alterations that occur after 10 weeks of treatment of adolescent female rats with DHT, before the appearance of hypertension. In the present study, we gave protective doses of vitamin $D$ to a group of hyperandrogenic female (HAF) rats. In an earlier study, a similar chronic vitamin D treatment regimen prevented cardiac failure and left ventricular hypertrophy in infant heart failure-prone SHR rats (12).

\section{MATERIALS AND METHODS Chemicals}

The normal Krebs-Ringer (nKR) solution that was used in the in vitro studies consisted of (in mmol/L) $\mathrm{NaCl} 119, \mathrm{KCl} 4.7$, $\mathrm{NaH}_{2} \mathrm{PO}_{4}$ 1.2, $\mathrm{MgSO}_{4}$ 1.17, $\mathrm{NaHCO}_{3} 24, \mathrm{CaCl}_{2}$ 2.5, glucose 5.5, and EDTA 0.034. A Ca ${ }^{2+}$-free Krebs solution containing (in $\mathrm{mmol} / \mathrm{L}$ ) $\mathrm{NaCl}$ 92, $\mathrm{KCl} 4.7, \mathrm{NaH}_{2} \mathrm{PO}_{4} 1.18, \mathrm{MgCl}_{2} 20$, $\mathrm{MgSO}_{4}$ 1.17, $\mathrm{NaHCO}_{3} 24$, glucose 5.5, EGTA 2, and EDTA 0.025 was used to relax smooth muscle. The temperature of the solution was kept at $37^{\circ} \mathrm{C}$, and it was bubbled with $5 \%$ $\mathrm{CO}_{2}, 20 \% \mathrm{O}_{2}$, and $75 \% \mathrm{~N}_{2}$, which stabilized the $\mathrm{pH}$ at 7.4. Norepinephrine (NE), Ach, and L-NG-nitroarginine methyl ester (L-NAME) was obtained from Sigma-Aldrich. Human recombinant insulin (Actrapid Penfill, $100 \mathrm{IU} / \mathrm{mL}$ ) was obtained from Novo Nordisk. Drugs were freshly prepared on the day of the experiment in an nKR solution.

\section{Animals}

The protocol for inducing experimental polycystic ovary syndrome has been previously described by Manneras et al. (13). Continuous-release pellets containing $7.5 \mathrm{mg}$ DHT (Innovative Research of America) were applied for 70 days. Releases of $83 \mu \mathrm{g} / \mathrm{d}$ for 90 days are guaranteed by the manufacturer. Under anesthesia (Nembutal, $45 \mathrm{mg} / \mathrm{kg}$ intraperitoneally; Phylaxia-Sanofi) in sterile conditions, 20 sexually adolescent (21-28 days old) female Wistar rats, which were provided by the Animal Facility of the Semmelweis University in agreement with Charles River and weighed 100-140 g at the beginning of the study, received subcutaneous pellets containing $7.5 \mathrm{mg}$ DHT implanted under the back skin (DHT group). Ten animals underwent sham operations (control group). After the surgical intervention, a mixture of $20 \mathrm{mg}$ amoxicillin and $4 \mathrm{mg}$ clavulanic acid (Augmentin; Glaxo Smith Kline) in $0.2 \mathrm{~mL}$ saline solution was administered intramuscularly to prevent infection.

Ten of the DHT-treated animals received weekly doses of $120 \mathrm{ng} / 100 \mathrm{~g}$ vitamin D (12) applied in injections of $1,25(\mathrm{OH})_{2}$ vitamin $\mathrm{D}_{3}$ (12) (Injectable Calcijex, $2 \mu \mathrm{g} / \mathrm{mL}$; Abbott Laboratories; $\mathrm{DHT}+\mathrm{D} 3$ group). The remaining 20 animals received vehicle. No medical or surgical complications were observed. Conventional rat food and tap water were provided ad libitum. After 8 weeks of treatment, an oral glucose tolerance test (OGTT) was performed under short ether narcosis. Blood glucose and plasma insulin were measured after overnight fasting and 120 minutes after an oral glucose load of $0.3 \mathrm{~g} / 100 \mathrm{~g}$ body weight given through a gauge $(15,16)$.
Blood glucose was measured by Decont Personal Akucheck (77 Electronics). For the insulin measurements, a Rat/Mouse Insulin ELISA was used (Millipore). Serum fructose-amine was determined by Roche 930010 test. This study conformed to the Principles of Laboratory Animal Care, National Institutes of Health publication no. 85-23 (revised 1985) and the Euroconform Hungarian Law on Animal Care (XXVIII/1998) and was approved by the institutional Animal Care Commission (Institutional Review Board approval: 22.1/ 2960/003/2009).

\section{Pressure Arteriography of Gracilis Arterioles}

After 10 weeks of treatment, animals were reanesthetized (Nembutal $45 \mathrm{mg} / \mathrm{kg}$ intraperitoneally). Their blood pressure was measured directly by cannulation of the carotid artery. After opening the iliofemoral region, the gracilis arteriole supplying the gracilis muscle, which measures $\sim 150 \mu \mathrm{m}$ in diameter in vivo, was removed and placed into a vessel chamber filled with nKR solution. The arteriole was cannulated at both ends with plastic microcannulas and extended to its in vivo length. Both cannulas were connected to pressureservo pumps (Living Systems), and the arterioles were pressurized in a no-flow condition to $50 \mathrm{~mm} \mathrm{Hg}$ intraluminal pressure.

The outer and the inner diameters of the arteries were measured by videomicroscopic microangiometry. In this setup, the glass-bottomed tissue bath was positioned in the light path of an inverse Leica microscope. A magnified picture of the vessel was formed with the aid of a video camera (Leica DFC320) and Leica QWin software. The digitized pictures were saved and off-line measurements of the inner and outer diameters were made using the Leica QWin image analyzing software.

Gracilis arterioles were allowed to equilibrate for $30 \mathrm{~min}-$ utes at $50 \mathrm{~mm} \mathrm{Hg}$ intraluminal pressure in an oxygenized nKR solution. The steady-state diameter was measured. The diameter was also measured during norepinephrine (NE) contraction after a 10 -minute incubation period with $10^{-6} \mathrm{~mol} / \mathrm{L}$ $\mathrm{NE}$. After recording the NE-diameter at $50 \mathrm{~mm} \mathrm{Hg}$, dosediameter curves were recorded in the presence of 30,60 , 120, 240, and $600 \mathrm{mU} / \mathrm{mL}$ of insulin, leaving an equilibration period of 8-10 minutes for each dose, which allowed a stable diameter to be reached and measured. After rinsing, NE was added to the organ bath in the same dose as previously described. After 10 minutes of incubation at $50 \mathrm{~mm} \mathrm{Hg}$, $10^{-6} \mathrm{~mol} / \mathrm{L}$ Ach was added to the organ bath, and after another 20 minutes the outer and inner diameters were measured. Then, $10^{-5} \mathrm{~mol} / \mathrm{L}$ L-NAME was administered, and after equilibrium was reached the diameters were measured again; at this step, equilibration required 25-30 minutes at $50 \mathrm{~mm}$ $\mathrm{Hg}$. Finally, the passive diameter was obtained after $20 \mathrm{~min}-$ utes incubation in a $\mathrm{Ca}^{2+}$-free Krebs solution. Segments were incubated for 20 minutes, and then the steady-state fully relaxed diameter was measured. The effect of insulin + NE was compared with the NE-induced contraction without insulin and with full relaxation. Calibrations were made with an etalon micrometer (Wild). Insulin-induced relaxations of precontracted segments were normalized to the NE-induced 
precontraction without insulin: $\left(\mathrm{R}_{\mathrm{Ins}}-\mathrm{R}_{\mathrm{NE}}\right) / \mathrm{R}_{\mathrm{NE}}$. The insulininduced relaxation of NE-precontracted segments was normalized to the relaxation induced in the same segments by the Ca-free free medium: $\left(\mathrm{R}_{\mathrm{Ins}}-\mathrm{R}_{\mathrm{NE}}\right) /\left(\mathrm{R}_{\text {Cafree }}-\mathrm{R}_{\mathrm{NE}}\right)$. In a similar manner, the Ach-relaxation and the effect of L-NAME were compared with NE-precontraction. Thus, all parameters are independent of absolute vessel diameter.

\section{Histology and Histometry}

Ovaries were removed, fixed with formaldehyde, stained with hematoxylin-eosin, and histologically examined. We detected polycystic morphology in the DHT-treated groups and normal ovaries in the control groups, as published earlier in Manneras and Yanes $(13,14)$. Morphometric measurements were made using the Pannoramic Viewer software (3D Histech).

\section{Statistics}

A repeated-measures analysis of variance (ANOVA) was used for the statistical analysis of the cumulative concentrationdiameter curves. A one-way ANOVA was applied to discrete parameters, e.g., body weights. Tukey test was used as a post hoc test. $P<.05$ was uniformly accepted as the threshold for statistical significance. Data are shown as mean \pm SEM.

\section{RESULTS}

\section{Basic Physiologic Parameters}

The mean arterial pressures were: control, $122 \pm 3 \mathrm{~mm} \mathrm{Hg}$; DHT, $123 \pm 6 \mathrm{~mm} \mathrm{Hg}$; and DHT $+\mathrm{D}_{3}, 123 \pm 4 \mathrm{~mm} \mathrm{Hg}$. The mean body weight in the two DHT-treated groups was significantly higher than in the control group. However, the two treatment groups did not differ from each other at the end of the experiment (control, $298 \pm 8 \mathrm{~g}$; DHT, $354 \pm 16 \mathrm{~g}$; $\mathrm{DHT}+\mathrm{D} 3,353 \pm 9 \mathrm{~g})$.

\section{Glucose Metabolism}

The fasting and 120-minute postload blood glucose and insulin values are presented in Table 1 . The blood glucose levels and the fasting insulin levels were not significantly different among the experimental groups. However, significant differences were found among the groups for the 120-minute postload insulin values. DHT-treated animals had higher plasma insulin levels than the control animals, and this difference was eliminated by the $\mathrm{D}_{3}$ vitamin treatment. Values for glycated proteins also did not differ (Table 1).

\section{Pressure Arteriography}

The relaxed inner radii of the gracilis arterioles were significantly larger in the DHT-only compared with the other two groups (DHT, $96 \pm 3 \mu \mathrm{m}$; control, $84 \pm 6 \mu \mathrm{m}$; DHT $+\mathrm{D}_{3}, 83$ $\pm 5 \mu \mathrm{m}$; both $P<.05)$. NE-contractions were reduced in DHT-treated animals, and this was mostly restored after parallel $\mathrm{D}_{3}$ vitamin treatment (Fig. $1 ; P<.05$ for both control vs. DHT and DHT vs. DHT $+\mathrm{D}_{3}$ ). Ach-dilations were severely diminished in the DHT-treated female animals (Table 1). Vitamin $\mathrm{D}_{3}$ treatment produced only a nonsignificant trend toward restoring relaxation. In the presence of Ach, the inhibition of NO synthesis with L-NAME caused contraction, which was missing in the DHT-treated groups, thus proving that vascular NO synthesis was altered in these vessels (Table 1).

Insulin administered to NE-precontracted gracilis arteriole segments induced concentration-dependent relaxation in the control animals (Fig. 2). This relaxing effect was much reduced in the DHT-treated group $(P<.001)$. The administration of vitamin $\mathrm{D}_{3}$ partially restored the insulininduced relaxation $(P<.001)$.

Another significant effect of vitamin $\mathrm{D}_{3}$ treatment was revealed when we compared the NE-induced contractions of segments before and after in vitro treatment with elevating concentrations of insulin. Typically, NE-induced contractions were more profound after insulin treatment (Fig. 3). This difference was reduced in vitamin $\mathrm{D}_{3}$-treated animals $(P<.05)$.

\section{DISCUSSION}

As a model of human polycystic ovary syndrome, 10 weeks of DHT treatment starting during adolescence in female rats (13, 14) induced significant arteriole alterations in our studies. We observed an increase in vascular diameter, a reduction of the

\section{TABLE 1}

\section{Results of oral glucose tolerance test.}

Blood sugar $0^{\prime}$

Blood sugar $120^{\prime}$

Insulin $0^{\prime}$

Insulin 120'

Glycated protein (fructoseamine)

Ach-induced relaxation (Ri Ach - Ri Ne)/Ri Ne

L-NAME-induced contraction (Ri Ach - Ri

$$
\text { LNAME)/Ri Ach }
$$

Note: The 120-minute postload insulin level in the DHT group was significantly higher than in the control group (*P<.01). Vitamin $\mathrm{D}$ treatment normalized the insulin response during the oral glucose tolerance test $\left({ }^{\ddagger} P<.001\right)$. There were no significant differences in other parameters: blood sugar $0^{\prime}, 120^{\prime}$, insulin $0^{\prime}$, and glycated protein levels. The Ach-induced relaxation was significantly greater in the control than the other two groups $\left({ }^{*}, t P<.05\right)$. The L-NAME-induced contraction was significantly lower in the DHT group than in the control group $(P<.05)$. $\mathrm{n}=10$ in each group. $\mathrm{DHT}=$ dihydrotestosterone.

Sara. Vascular insulin resistance in PCOS. Fertil Steril 2012.

$$
\text { Control }(n=10)
$$

$5.31 \pm 0.15 \mathrm{mmol} / \mathrm{L}$

$6.11 \pm 0.11 \mathrm{mmol} / \mathrm{L}$

$0.42 \pm 0.02 \mathrm{ng} / \mathrm{mL}$

$0.71 \pm 0.14 \mathrm{ng} / \mathrm{mL}$

$157 \pm 3 \mathrm{mmol} / \mathrm{L}$

$1.22 \pm 0.29$

$0.21 \pm 0.10$

$$
\text { DHT (n = 10) }
$$

$5.35 \pm 0.24 \mathrm{mmol} / \mathrm{L}$

$6.36 \pm 0.2 \mathrm{mmol} / \mathrm{L}$

$0.42 \pm 0.03 \mathrm{ng} / \mathrm{mL}$

$1.42 \pm 0.33 \mathrm{ng} / \mathrm{mL}^{*}$

$151 \pm 4 \mathrm{mmol} / \mathrm{L}$

$0.48 \pm 0.14^{*}$

$-0.03 \pm 0.05^{*}$

$$
\begin{gathered}
\text { DHT + vitamin D }(\mathbf{n}=\mathbf{1 0}) \\
5.18 \pm 0.27 \mathrm{mmol} / \mathrm{L} \\
7.09 \pm 0.13 \mathrm{mmol} / \mathrm{L} \\
0.45 \pm 0.04 \mathrm{ng} / \mathrm{mL}^{\prime} \\
0.48 \pm 0.07 \mathrm{ng} / \mathrm{mL}^{\ddagger} \\
156 \pm 4 \mathrm{mmol} / \mathrm{L} \\
0.70 \pm 0.10^{\dagger} \\
0.02 \pm 0.02
\end{gathered}
$$




\section{FIGURE 1}

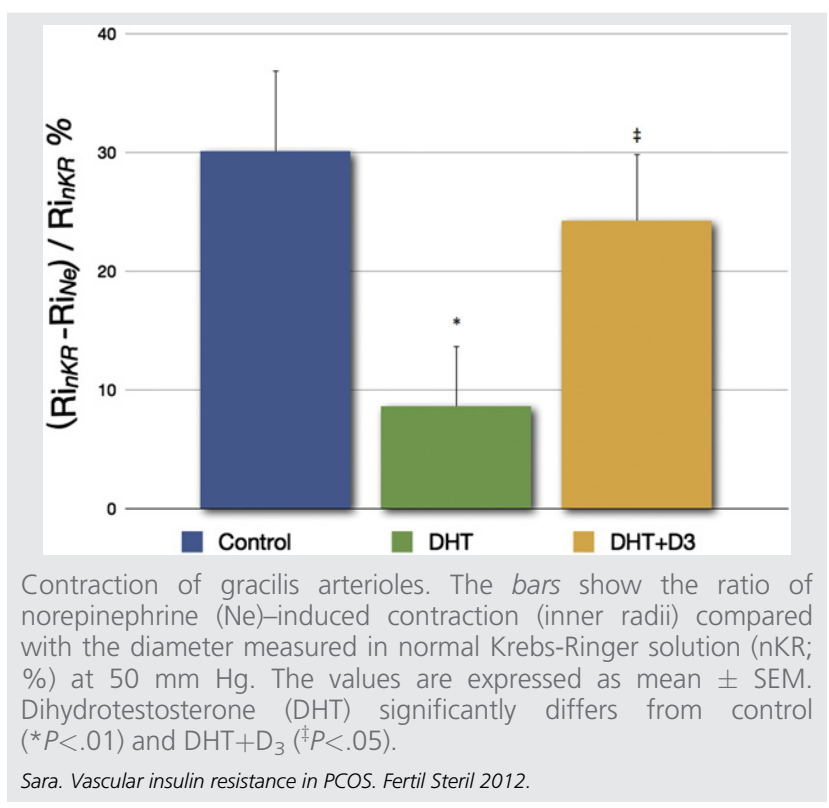

NE-induced tone, and diminishing endothelial-dependent dilation. Insulin-induced relaxation was also diminished. Chronic vitamin $\mathrm{D}_{3}$ treatment restored vascular diameter and improved NE-induced contraction. In animals treated with vitamin $D_{3}$, the insulin-evoked relaxation returned to the control level. Although increased insulin resistance in human PCOS disease and in DHT-treated female animals has been described previously, the alteration of the well known vasodilator activity of insulin was not studied. In addition, the artery resistance effects of vitamin $\mathrm{D}_{3}$ treatment, which improves both the alterations associated with PCOS (Figs. 1 and 2) and insulin resistance (Table 1), had not yet been investigated.

The experimental model used in the present study has been proven to be an adequate rat PCOS model $(13,14)$. It has been shown that an 8-12-week DHT treatment identical to the one that we used induces PCOS and significantly, approximately threefold, increases androgen levels in female rats (13). Yanes has detected several metabolic abnormalities (14). Despite normal $E_{2}$ levels, DHT-treated animals exhibited estrus cycle dysfunction. A significant increase in body weight was detected, which was also noted in the present study. This difference in body weight may be a consequence of an androgen-dependent increase in adiponectin receptor expression and low serum levels of adiponectin $(17,18)$. The effect on body weight was not influenced by vitamin $\mathrm{D}_{3}$ treatment. Based on elevated blood glucose and insulin levels, Yanes hypothesized that insulin resistance occurs in hyperandrogenic female rats (14). This hypothesis is supported by our measurements, because the OGTT did not show glucose metabolism abnormalities, and no difference was found in the fasting blood insulin levels, but a threefold increase was noted in the 2-hour post-glucose load value compared with the control animals. Considering these facts, our experimental model was suitable for studying early initial abnormalities and vascular damage. Although type 2 diabetes mellitus had not yet developed, the 2-hour

\section{FIGURE 2}
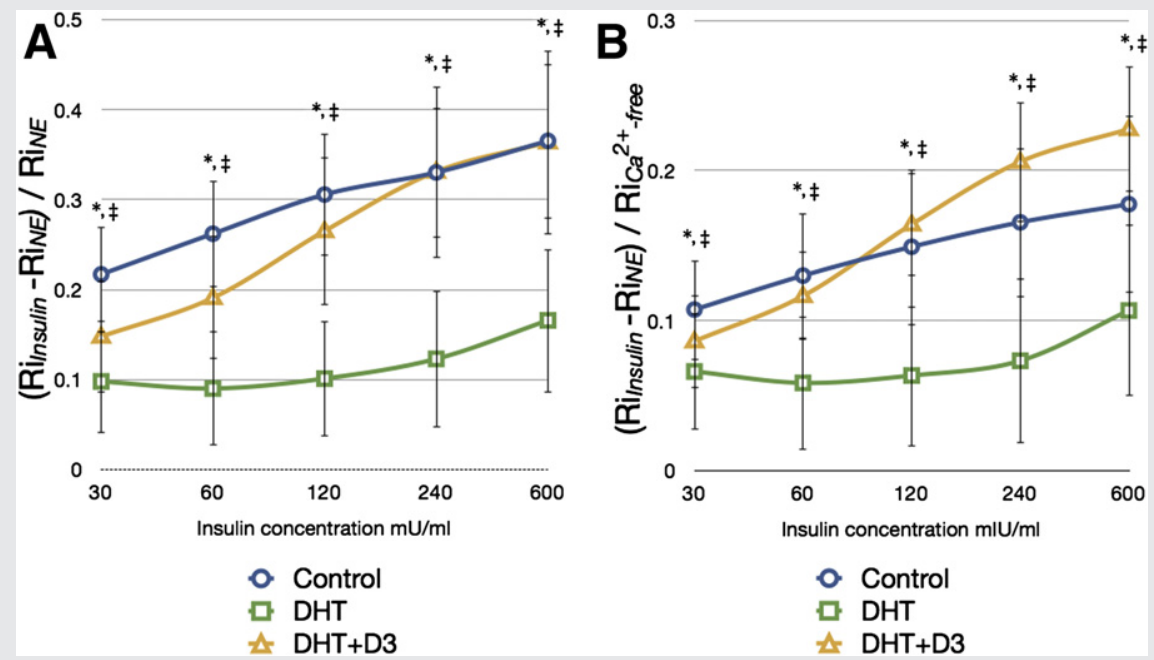

(A) Insulin-induced vascular tone ( $T$ insulin) as a function of norepinephrine (NE) tone in gracilis arterioles in the three experimental groups. The values on the abscissa show the inner radii ratios of insulin-induced and NE-induced tone at $50 \mathrm{~mm} \mathrm{Hg}$. The $x$ axis shows the different insulin concentrations. Values are expressed as mean \pm SEM. ${ }^{*}$ The dihydrotestosterone $(\mathrm{DHT})$ group differs significantly from control $(P<.0001)$. ${ }^{\ddagger}$ The $\mathrm{DHT}+\mathrm{D} 3$ group differs significantly from the DHT group $(P<.0001)$. (B) $\mathrm{T}$ insulin as a function of $\mathrm{Ca}$-free relaxation in gracilis arterioles in the three experimental groups. The values on the abscissa show the inner radii ratios of insulin-induced tone in the $\mathrm{Ca}^{2+}$-free solution compared with the NE-induced tone at $50 \mathrm{~mm} \mathrm{Hg}$. The $x$ axis shows different concentrations of insulin levels. The values are expressed as mean $\pm S E M$. *The DHT group is significantly different from the control group $(P<.01)$. ${ }^{\ddagger}$ The DHT+D3 group is significantly different from the DHT group $(P<.01)$. Sara. Vascular insulin resistance in PCOS. Fertil Steril 2012. 


\section{FIGURE 3}

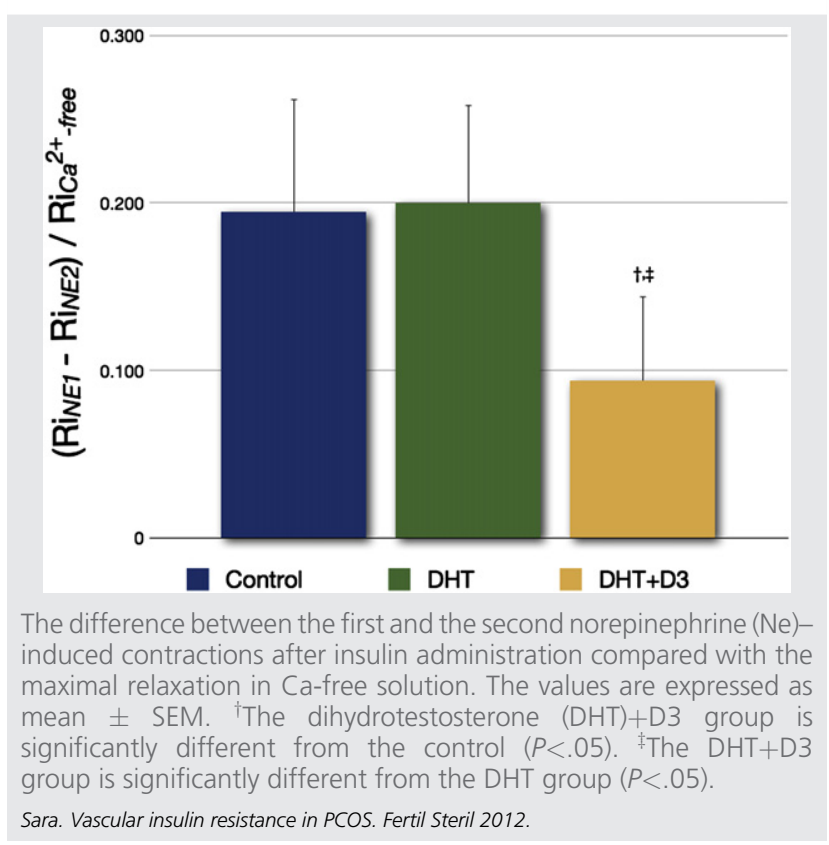

insulin value of the OGTT showed insulin resistance. This early glucose metabolism abnormality was fully prevented by vitamin $\mathrm{D}_{3}$ treatment.

The DHT treatment applied by Yanes et al. resulted in hypertension when administered for a longer period of time (90 days) (14). During our 70-day treatment, no significant differences were found among the blood pressure values of the experimental groups. This result means that the changes detected are directly attributable to either hyperandrogenism or hyperinsulinemia/insulin resistance and are independent of blood pressure. During the 90-day treatment, Yanes et al. detected an increase in spontaneous proteinuria, morphologic renal damage, and elevated transforming growth factor $\alpha$, leptin, and cholesterol levels, indicating increased oxidative stress and increased NADPH oxidase 4 expression (14). These metabolic abnormalities may influence the pharmacologic response of the arteries.

The direct vascular effects of chronic hyperandrogenism must also be considered. The predominant direct vascular effect of androgens is vasorelaxation. Both DHT, dependent on dose, and T block the L-type voltage-operated calcium channels, whereas high concentrations of T induce direct vasorelaxation because of its Ca-antagonist effect and increased cyclic adenosine monophosphate production in the rat aorta (19). A similar but slightly weaker Ca-dependent vasorelaxant effect of $E_{2}$ was noted in rat aorta after phenylephrine precontraction (20). Chronic low-dose T administration improved the risk of myocardial ischemia (21), lipid profile, and insulin resistance because of its direct vasoactive and metabolic effects (22). Despite progressive atherosclerosis, chronic T treatment enhanced Ach-dependent, endothelium-dependent relaxation in ovariectomized female monkeys, although it did not influence direct smooth muscle-dependent relaxation elicited by sodium nitroprusside (23). Yanes et al. found elevated intrarenal angiotensinogen levels and angiotensin I-converting enzyme expression as well as decreased angiotensin II receptor 1 expression in HAF rats (14). Human experiments have shown microvascular dysfunction in PCOS, as indicated by the inhibition of Ach-dependent vasodilation (5). Endothelial dysfunction and damage has been shown to be enhanced by increased inflammatory and soluble activation markers (24). Paraoxonase- 1 and flow-mediated dilation have been shown to be useful predictors of endothelial dysfunction (25). The effects of chronic androgen treatment are currently a subject of debate. On the one hand, these effects are species specific, but on the other hand, distinct effects of the different androgenic compounds probably also exist.

The pharmacologic effects on vessel reactivity of some products used in PCOS treatment are still under investigation. Meyer noted the importance of accounting for not only the hyperandrogenic symptoms but also the changes in glucose metabolism, stiffness, and pulse-wave velocity during PCOS treatment; treatment with metformin rather than high-dose oral contraceptives has been suggested (26, 27). Agarwal et al. (6) has shown that metformin decreases the arterial stiffness, aortic and brachial pulse-wave velocity, and aortic augmentation index and improves endothelium-dependent and independent vascular responses $(20,28,29)$. Increased flow-mediated vasodilation has been considered during insulin-sensitizing treatment with metformin or pioglitazone in PCOS women (7). The treatment protocols used in PCOS often modify the cardiovascular risk of patients $(6,26)$. High-dose oral contraceptives usually increase the risk; metformin has been proven to decrease the risk, and low-dose oral contraceptives probably have no effect $(6,26)$.

In our experiments, vitamin $\mathrm{D}_{3}$ treatment significantly decreased the vascular insulin resistance caused by DHT. During NE-induced precontraction, DHT treatment decreased insulin-dependent relaxation, thus producing vascular insulin resistance. However, similar relaxation was observed in the control and vitamin $\mathrm{D}_{3}$-treated groups (Fig. 2). In response to insulin, the NE sensitivity of the vitamin $\mathrm{D}_{3}$-treated group remained practically unchanged (Fig. 3). In the control and DHT-treated groups, a 20\% increase in contractility was observed after rinsing and during the second compared with the first NE-contraction (Fig. 3). No differences were found between the first and second NE-contractions in the vitamin $\mathrm{D}_{3}-$ treated group, which suggests that vitamin $\mathrm{D}_{3}$ treatment improves NE sensitivity. However, the most prominent insulindependent relaxation was detected in the vitamin $\mathrm{D}_{3}$-treated group (Fig. 2B). Comparing the insulin-dependent relaxation to Ach-relaxation, highly significant differences were noted. Ach caused stronger relaxation in the control group than in the two treated groups. Moreover, this difference remained the same or increased during L-NAME blockade. These results suggest that the relaxing effect of insulin is independent from $\mathrm{NO}$ in the gracilis arterioles and that vitamin $\mathrm{D}_{3}$ restores normal vascular tone independently from the NO system. NO-mediated relaxation of insulin in human muscle arterioles $(30,31)$ and $\mathrm{Na}^{+}-\mathrm{K}^{+}$adenosine triphosphatase may play independent roles in human vessel relaxation $(32,33)$. Luis et al. have presented an NO-independent insulin-mediated direct mechanism of relaxation on renal efferent arterioles in 
rabbits (34). Physical exercise has been found to increase the blood flow stimulated by insulin in skin arterioles by activating $\mathrm{K}\left(\mathrm{Ca}^{2+}\right)$ channels (35). Our results demonstrate that DHT treatment probably partially decreases NO-mediated relaxation. During DHT treatment, a difference was noted in Ach-relaxation. By blocking the NO pathway, minor contractions were detected, suggesting the local involvement of the prostanoid system $(11,36)$ and muscarinic Ach receptors (37) in addition to the NO pathway. It has been shown that insulin-dependent relaxation of the large vessels (aorta) and gracilis arterioles are predominantly mediated by NO and endothelium-derived hyperpolarizing factor/potassium channels, respectively (38).

Wong et al.'s results demonstrate that vitamin $\mathrm{D}_{3}$ has a direct vascular effect: lowering prostanoid-dependent vasoconstriction in spontaneously hypertensive rats (SHRs) to the level of Wistar-Kyoto rats (11). Therefore, a role for vitamin $\mathrm{D}_{3}$ deficiency has been suggested in the pathomechanism of hypertension, because vitamin $\mathrm{D}_{3}$ treatment also decreases endothelial dysfunction in SHRs (11). Many authors have suggested that a low serum level of vitamin $\mathrm{D}_{3}$ plays a role in the insulin resistance observed in PCOS, which may be corrected by vitamin $\mathrm{D}_{3}$ replacement (39). In type 2 diabetes, vitamin $\mathrm{D}_{3}$ improved the flow-mediated vasodilation of the brachial artery (9). The latter study demonstrated the direct vascular effects of vitamin $\mathrm{D}_{3}$ treatment: the flow-mediated dilation of the brachial artery was significantly diminished in patients with low serum levels of vitamin $\mathrm{D}_{3}$. Under experimental conditions, a 6 -week vitamin $\mathrm{D}_{3}$ treatment normalized Ach-relaxation in SHRs. However, this effect was not related to intracellular calcium balance, which remained unchanged during the whole treatment; instead, it correlated with decreases in reactive oxygen free radicals and cyclooxygenase-1 expression (11). In light of the above, when interpreting the effects of vitamin $D_{3}$ under hyperandrogenic circumstances, one must consider the direct vascular effect of vitamin $\mathrm{D}_{3}$ and DHT interactions as well as the indirect vascular effects caused by improving insulin resistance. The stability of the NE-induced contractions in vitamin $\mathrm{D}_{3}$-treated rats demonstrates the role of vitamin $\mathrm{D}_{3}$ in preserving vascular reactivity. According to studies performed on rat aorta, vitamin $\mathrm{D}_{3}$ plays a role in maintaining vascular reactivity and the vascular effects of sex hormones via creatine kinase activity (40). Increased vascular endothelial growth factor expression may also take part in the chronic vasoprotective effects of vitamin $\mathrm{D}_{3}$ (41).

\section{CONCLUSIONS}

This is the first study investigating the vascular adaptation and insulin sensitivity of gracilis arterioles in a PCOS model. Our results show a partial NO dependency of vascular reactivity changes caused by hyperandrogenism. In our experimental model, vitamin $\mathrm{D}_{3}$ restored the systemic insulin response as well as the NO-independent insulin-induced relaxation and NE sensitivity of the gracilis arterioles. This is the first study demonstrating vascular insulin resistance of the gracilis arterioles and the counteracting effect of vitamin $\mathrm{D}_{3}$ in an experimental PCOS model.
Acknowledgments: The authors express their gratitude to Mr. Csaba Revesz, Mrs. Ildikó Murányi, and Ms. Agnes Novak for their devoted efforts in solving technical problems in the laboratory work.

\section{REFERENCES}

1. Hart R, Doherty DA, Mori T, Huang RC, Norman RJ, Franks S, et al. Extent of metabolic risk in adolescent girls with features of polycystic ovary syndrome. Fertil Steril 2011;95:2347-53.

2. Dokras A. Cardiovascular disease risk factors in polycystic ovary syndrome. Semin Reprod Med 2008;26:39-44.

3. Lakhani K, Constantinovici N, Purcell WM, Fernando R, Hardiman P. Internal carotid artery haemodynamics in women with polycystic ovaries. Clin Sci 2000;98:661-5.

4. Meyer C, McGrath BP, Teede HJ. Overweight women with polycystic ovary syndrome have evidence of subclinical cardiovascular disease. J Clin Endoc Metab 2005;90:5711-6.

5. Lakhani K, Leonard A, Seifalian AM, Hardiman P. Microvascular dysfunction in women with polycystic ovary syndrome. Hum Reprod 2005;20: 3219-24.

6. Agarwal N, Rice SP, Bolusani H, Luzio SD, Dunseath G, Ludgate M, et al. Metformin reduces arterial stiffness and improves endothelial function in young women with polycystic ovary syndrome: a randomized, placebo-controlled, crossover trial. J Clin Endocr Metab 2010;95:722-30.

7. Naka KK, Kalantaridou SN, Kravariti M, Bechlioulis A, Kazakos N, Calis KA, et al. Effect of the insulin sensitizers Metformin and Pioglitazone on endothelial function in young women with polycystic ovary syndrome: a prospective randomized study. Fertil Steril 2011;95:203-9.

8. Thys-Jacobs S, Donovan D, Papadopoulos A, Sarrel P, Bilezikian JP. Vitamin D and calcium dysregulation in the polycystic ovarian syndrome. Steroids 1999;64:430-5.

9. Yiu YF, Chan YH, Yiu KH, Siu CW, Li SW, Wong LY, et al. Vitamin D deficiency is associated with depletion of circulating endothelial progenitor cells and endothelial dysfunction in patients with type 2 diabetes. J Clin Endocr Metab 2011;96:E830-5.

10. Kotsa K, Yavropoulou MP, Anastasiou O, Yovos JG. Role of vitamin D treatment in glucose metabolism in polycystic ovary syndrome. Fertil Steril 2009;92:1053-8.

11. Wong MS, Delansorne R, Man RY, Svenningsen P, Vanhoutte PM. Chronic treatment with vitamin $D$ lowers arterial blood pressure and reduces endothelium-dependent contractions in the aorta of the spontaneously hypertensive rat. Am J Physiol Heart Circ Physiol 2010;299:H1226-34.

12. Przybylski R, McCune S, Hollis B, Simpson RU. Vitamin D deficiency in the spontaneously hypertensive heart failure (SHHF) prone rat. Nutr Metab Cardiovas 2010;20:641-6.

13. Mannerås L, Cajander S, Holmang A, Seleskovic Z, Lystig T, Lönn M, et al. A new rat model exhibiting both ovarian and metabolic characteristics of polycystic ovary syndrome. Endocrinology 2007;148:3781-91.

14. Yanes LL, Romero DG, Moulana M, Lima R, Davis DD, Zhang H, et al. Cardiovascular-renal and metabolic characterization of a rat model of polycystic ovary syndrome. Gender Medicine 2011;8:103-15.

15. Pan Y, Cai B, Wang K, Wang S, Zhou S, Yu X, et al. Neferine enhances insulin sensitivity in insulin resistant rats. J Ethnopharmacol 2009;124:98-102.

16. Marchand KC, Arany EJ, Hill DJ. Effects of atorvastatin on the regeneration of pancreatic $\beta$-cells after streptozotocin treatment in the neonatal rodent. Am J Physiol Endocr Metab 2010;299:E92-100.

17. Tan BK, Chen J, Digby JE, Keay SD, Kennedy CR, Randeva HS. Upregulation of adiponectin receptor 1 and 2 mRNA and protein in adipose tissue and adipocytes in insulin-resistant women with polycystic ovary syndrome. Diabetologia 2006;49:2723-8.

18. Trolle B, Lauszus FF, Frystyk J, Flyvbjerg A. Adiponectin levels in women with polycystic ovary syndrome: impact of metformin treatment in a randomized controlled study. Fertil Steril 2010;94:2234-8.

19. Montaño LM, Calixto E, Figueroa A, Flores-Soto E, Carbajal V, Perusquía M Relaxation of androgens on rat thoracic aorta: Testosterone concentration dependent agonist/antagonist L-type $\mathrm{Ca}^{2+}$ channel activity, and 
$5 \beta$-dihydrotestosterone restricted to L-type $\mathrm{Ca}^{2+}$ channel blockade. Endocrinology 2008;149:2517-26.

20. Castillo C, Castillo EF, López J, López RM. Testosterone inhibits the contractile responses to phenylephrine associated with the release of intracellular calcium in rat aorta. Gac Med Mex 2006;142:1-8.

21. Miller KK, Biller BMK, Schaub A, Pulaski-Liebert K, Bradwin G, Rifai N, Klibanski A. Effects of testosterone therapy on cardiovascular risk markers in androgen-deficient women with hypopituitarism. J Clin Endocr Metab 2007:92:2474-9.

22. Cornoldi A, Caminiti G, Marazzi G, Vitale C, Patrizi R, Volterrani M, et al. Effects of chronic testosterone administration on myocardial ischemia, lipid metabolism and insulin resistance in elderly male diabetic patients with coronary artery disease. Int J Cardiol 2010;142:50-5.

23. Adams MR, Williams JK, Kaplan JR. Effects of androgens on coronary artery atherosclerosis and atherosclerosis-related impairment of vascular responsiveness. Arterioscler Thromb Vasc Biol 1995;15:562-70.

24. Diamanti-Kandarakis E, Alexandraki K, Piperi C, Protogerou A, Katsikis I, Paterakis $\mathrm{T}$, et al. Inflammatory and endothelial markers in women with polycystic ovary syndrome. Eur I Clin Invest 2006;36:691-7.

25. Soyman Z, Noyan V, Tulmac M, Yucel A, Sagsoz N, Bayrak T, et al. Serum paraoxonase 1 activity, asymmetric dimethylarginine levels, and brachia artery flow-mediated dilatation in women with polycystic ovary syndrome. Fertil Steril 2011;95:1067-72.

26. Meyer C, McGrath BP, Teede HJ. Effects of medical therapy on insulin resistance and the cardiovascular system in polycystic ovary syndrome. Diabetes Care 2007;30:471-8

27. Teede HJ, Meyer C, Hutchison SK, Zoungas S, McGrath BP, Moran LJ. Endothelial function and insulin resistance in polycystic ovary syndrome: the effects of medical therapy. Fertil Steril 2010;93:184-91.

28. Orio F, Palomba S, Cascella T, De Simone B, Manguso F, Savastano S, et al. Improvement in endothelial structure and function after Metformin treatment in young normal-weight women with polycystic ovary syndrome: results of a 6-month study. J Clin Endocr Metab 2005;90:6072-6.

29. Jensterle M, Sebestjen M, Janez A, Prezelj J, Kocjan T, Keber I, et al. Improvement of endothelial function with metformin and rosiglitazone treatment in women with polycystic ovary syndrome. Eur J Endocrinol 2008;159: 399-406.
30. Steinberg HO, Brechtel G, Johnson A, Fireberg N, Baron AD. Insulin-mediated skeletal muscle vasodilatation is nitric oxide dependent. A novel action of insulin to increase nitric oxide release. J Clin Invest 1994;94: 1172-9.

31. Scherrer U, Randin D, Vollenweider P, Vollenweider L, Nicod P. Nitric oxide release accounts for insulin's vascular effects in humans. J Clin Invest 1994:94:2511-5.

32. Tack CJ, Lutterman JA, Vervoot $G$, Thien $T$, Smits $P$. Activation of the sodium-potassium pump contributes to insulin-induced vasodilatation in humans. Hypertension 1996;28:426-32.

33. Yki-Järvinen $\mathrm{H}$, Utriainen $\mathrm{T}$. Insulin-induced vasodilatation: physiology or pharmacology? Diabetologia 1998;41:369-79.

34. Luis $A$, Juncos $L A$, Ito $S$. Disparate effects of insulin on isolated rabbit afferent and efferent arterioles. J Clin Invest 1993;92:1981-5.

35. Ghafouri S, Hajizadeh S, Mani AR. Enhancement of insulin-induced cutaneous vasorelaxation by exercise in rats: A role for nitric oxide and $\mathrm{K}\left(\mathrm{Ca}^{2+}\right)$ channels. Eur J Pharmacol 2011;652:89-95.

36. Gonzales RJ, Ghaffari AA, Duckles SP, Krause DN. Testosterone treatment increases thromboxane function in rat cerebral arteries. Am J Physiol Heart Circ Physiol 2005;289:H578-85.

37. Gericke A, Sniatecki JJ, Mayer VG, Goloborodko E, Patzak A, Wess J, et al. Role of M1, M3, and M5 muscarinic acetylcholine receptors in cholinergic dilation of small arteries studied with gene-targeted mice. Am J Physiol Heart Circ Physiol 2011;300:H1602-8.

38. Peuler JD, Johnson BA, Phare SM, Sowers JR. Sex-specific effects of an insulin secretagogue in stroke-prone hypertensive rats. Hypertension 1993;22: 214-20.

39. Ngo DT, Chan WP, Rajendran S, Heresztyn T, Amarasekera A, Sverdlov AL, et al. Determinants of insulin responsiveness in young women: impact of polycystic ovarian syndrome, nitric oxide, and vitamin D. Nitric Oxide 2011;25:326-30

40. Somjen D, Posner GH, Stern N. Less calcemic vitamin D analogs enhance creatine kinase specific activity and modulate responsiveness to gonadal steroids in the vasculature. J Steroid Biochem 2006;101:232-8.

41. Cardus A, Panizo S, Encinas M, Dolcet X, Gallego C, Aldea M, et al. 1,25-Dihydroxyvitamin D3 Regulates VEGF production through a vitamin D response element in the VEGF promoter. Atherosclerosis 2009;204:85-9. 